\title{
Balada apokrifoen eta kritikarien saltsa-maltsez
}

\author{
PATRI URKIZU \\ (UNED)
}

ASPALDITXO gertatu zen. K.a. IV. mendean Grezia aldean. Delako Heraklides Pontiko eta Dionisio Ernegatua beti zebiltzan eztabaidaka, kalapita amaigabean. Bata, Heraklides, oso dotorea zen, jauntxoen antzera jazten, ibiltzen eta mintzatzen zen. Besteak, Dionisiok, ospe gutxiago ez ezik fama txarra zuen, egia esateko, taberna eta putetxe zale amorratua omen. Baina azken honek, halere, aski argia baitzen, Parthenopaeus deitu tragedia idatzi zuen, esanez Sofoklesek idatzia eta berak edirena zela. Heraklidesek benetazkotzat jo zuen aurkikuntza, eta Dionisiok aldarrikatu zuenean ez zela hala, bera zela egilea, ez zuen sinistu Heraklidesek, ez zion benetazkotasunaren ideiari amorrik eman nahi izan. Orduan, Dionisiok eztabaida hartan esan zuen obrak akrostiko bat gordetzen zuela non azken buruan mezu hau irakur zitekeen:

Tximu zaharra ez da tranpan eroriko.

Noski, eroriko dela.

Heraklidesek ez daki deus letra kontuez.

Eta antza denez, honetaz azkenean ohartu zenean Heraklides eta konturatu zenean zein oker zebilen, lotsak hartuta gorri-gorri gelditu omen zen, eztabaida behin betirako amaiturik.

Bada beste antzeko gertaera gertuagorik. Hau 1950ean eta Ameriketan gertatu zen Biblia exegeten artean. Paul Coleman-Norton jauna, Princeton Unibertsitateko irakaslea zen eta errebista bibliko ospetsu batean idatzi zuen, San Mateoren Ebangelioko sermoi zati berri bat grekeraz aurkitu zuela Marokoko mezkita batean beste eskuzkribu arabiar batzuen artean. Testuak Mateo 24, 22-koari jarraikitzen zion. Horrela Jesusek zioenean, zerbitzari gaiztoa hipokritekin batera kondenatua izanen dela, eta han izanen da nigar eta hortz garraskots, dizipulu bati dudak eta kezkak sortu zitzaizkiola eta itaundu zuenean, zer gertatuko da, orduan, hortzkabeekin, ihardetsi zuela Jesusek, benetan diotsuet, fede guttiko gizonak, ororentzat izanen dela hortzik.

Ikus dezakegunez, tabernazale zaharrak eta irakasle unibertsitari modernoak bazuten ardura nagusi bat, beste egitekoen artean, umorez adarra eta harpa jotzearena, alegia. 
Kristo aitzin bizi izan ziren idazle judu zenbaitek idazten zituzten testuak, - apokaliptikoak izan ala ez- Bibliako arbasoenak bailiran jotzen zituzten, profeten ondoko hutsunea betetzearren. Testu hauek ez zuten, beraz, engainatzeko asmorik, hots, lege hizkeran esaten denez, mens rea, eta faltsutze hauek pseudoepigrapha deitu zituzten.

Hiri eta eliza anitzek beren iragan denboren ospea azpimarratu nahi zutenean lekuko faltsuak asmatzen ohi zituzten arte handiz. Halaber, eskoletan ere idazle eredugarrien pastitxeak egiten irakasten zen.

Honela bada, gertatu zen idazle eredu eta miretsienen obrak gero eta gehiago eskatzen zirela eta eskaintza baino handiagoa zenez eskaera, testu faltsuak asmatu beharrean aurkitzen zirela. Alexandriako Bibliotekak, adibidez, liburuzainen eta langileen artean bazituen poetak eta eruditoak, zeinek biltze eta zaintze lanez kanpo, klasikoak imitatzen zituzten eta hauen obra berriak edireiten. Horrela pergaminoen merkatuan etorki iluneko Eskilo, Sofokles eta Euripides pila zebilen zokoz-zoko.

Berdin gertatu zen geroago, Zesar, Zizeron, Plauto eta Terenzioren idazlanekin. Varron gramatikariak, adibidez, Plautorenak bezala ematen ziren ehunda hogeitahamar obretarik ehunda bederatzi faltsutzat joz, hogeita bat soilik kontsideratu zituen benetazkotzat.

Leku urrun, galdu eta iritsiezin batean aurkitutako eskuzkribua, topos-a, topikoa, ohiko leloa bilakatu zen.

Erdi Aroan, Antzinatean gertatu zen bezala faltsifikatzioneak ugaritu bide ziren, hauek berekin kritikariak eta egia-biltzaileak sorrarazi zuten arren.

Nazio berriek beren nortasun nazionala eraiki, indartu, eta finkatzearren gogoko iragan noblea Goi Erdi Aroan asmatzen saiatu ziren, inolako lotsarik gabe. Adibidez, Godofredo Monmouth-ekoak Britainia Handiko Erregeen Historia idazterakoan bere adiskide erudito batek utzitako eta gales amahizkuntzan izkiribatua zenetik itzulitako kontuak zirela azpimarratzen zuen.

Ohikoa zen ere hiri guztiek beren arbaso sortzaileen artean Troiako Gerlan aritutako gerlari ospetsune bat bilatzea.

Legegizon batzuek, alabaina, esate baterako Inozenzio IIIa aitasaindua ospetsua egin zen eskuzkribuak ikusi eta zigiluei begirada azkar bat botatzea aski zitzaiolako bereizteko agiria benetazkoa ala faltsua zen.

Dena den, ugariak ziren agiri faltsuak eta askok egiazkoak bezala jarraitzen zuten izaten. Grazianoren Decretum-ak, adibidez, eskubide kanonikoaren legedi nagusiak bostehunen bat testu faltsu jaso zituen.

Halaberetsu, Corpus Epigraphicum Latinum delakoan bildu 144.044 inskripzioetarik 10.576 dira gezurrezkoak, faltsuak, hau da, asko eta asko Errenazimenduko antikuari irudimentsuek asmatuak.

Ez zen hau soilik mendebaldean gertatzen Txina aldean ere faltsifikatzaileek paperaren kolorea aldatzen ohi zuten lastozko teilatutikan erorarazitako euri tantez , eta gero papera espreski gaizki tratatzen zuten agiri zaharraren itxura har zezan. 
Kasu gehienetan faltsariek poema epikoetako pertsonai historikoei lekukotasunek pentsaraz zezaketen baino ekintza, sentimendu eta hitz dotoreagoak eransten zizkieten. Amodioa zen faltsutzearen arrazoirik garrantzitsuena, portaera honen arrazoi nagusia.

Ikusi dugun bezala Dionisio eta Coleman-Norton-en kasuan, ordea, irribarre egitea, adarra jotzea eta mementu atsegin batzu pasatzea, libertitzea besterik ez zuten helburutzat.

Alabaina, Erasmo Erroterdamekoa Errenazimenduan altxatu zen ozenki, gezurraren gainean jasotzen eta eraikitzen ari zen literatur mundu haren aurka, eta San Jeronimoren bizitzan Erdi Aroko legenda asko salatu zituen, hauetan sendatze miragarri eta giza gainetikakoen parte hartzeak ugari ageri baitziren, benetazko gertakuntzak itxuraldatuz.

Errenazimendu garaian Erasmorekin batera Isaac Casaubon, Henri Estienne XVI. mendeko helenistarik jakintsuenetarikoaren suhia, eta Jose Justo Eskaligero izan ziren kritikaririk zorrotzenak eta ahalegindu zirenak gezurrak bortizki salatzen. Hala, Eskaligero izan zen trebeena Nanni dominiko ospetsuaren kronologia kritikatzen eta honen delirioak itsusten.

Casaubon-ek, protestante zintzo, fin eta egiazale zenez, Leidenen 1606an plazaratu Thesaurus temporum liburuan zioen, ez zuela ikusten zein ongarri arraio ekar ziezaioketen benetazko historiari zoro haien asmakizunek.

Modu beretsuan Jan van Garp, alias Goropio, historiagile holandesak ediren zuen Nanniren Arkilokoa faltsifikazio bat zela. Amberesen argitaratu zuen Origines Antwerpiannae, 1569, obran kritikez aparte saiatzen zen ere bere ikuspegi berezia munduko historiaz ematen. Honetan holandesak adierazten zuen Uholde Handiaren aurretik bizi ziren herrialde batzuen ondorengoak zirela, eta beren hizkuntza, silaba bateko hitzez betea zenez, Adanen hizkuntza bera zela. Hau frogatzeko era ezberdineko kontuak asmatu zituen, hala nola Psametiko erregearen esperimentua. Honek itxi omen zituen bi haur gela batean eta ez omen zien hizkuntzarik irakatsi, baina haurrek bere gisa - bekoseskatzen omen zuten, eta nola hitz honek frisieraz ogia esan nahi duen, argi zegoen besterik gabe frisiarrak zirela eta ez egiptoarrak munduko lehen arraza.

Beste frisiar argi batek, Suffridus Petri-k frisieraren historiari bizitza berria eman nahi izan zion ere eta latin dotore batean idatzi zuen Apologia ..pro antiquitate et origine Frisiorum... (Franeker, 1603). Ohiko jantziz apaindu zuen ixtorioa, alegia, artxibo eta eskuzkribu galdu eta izkutu batzuetatik hartuak zituela, etorkiz frisiera hizkuntzan zirenak, baina alfabeto grezierazkoan ipiniak. Emmio delako batek salatu zuen apokrifoa eta erronka bota etorkizkoak erakuts zitzan, baina Petriren defentsa oso bizkorra izan zen, erantzunez galdutako testuak eta herri kantak Liviok eta Tazitok aipatzen zituzten erromatarren eta germanoen carmina haiek bezalakoak zirela, eta historialariek ez bazituzten kontserbatu haiek berak lortutakoak baietz. Eta erantsi zuen, herri iturburu haiek fantasiaz beterik bazeuden, hauek aztertuak behar zutela izan, eta historialari on batek ez zituela antzinako kontuak abandonatu behar fantasia zenbait bertan txertatuak izanagatik, baizik eta fantasia hauek behar zituela arakatu, ikertu eta argitu antzinatasunen mesedetan. 
Kontestu honetan ez da harrigarri gertatzen XVI. mende bukaeran bi eskribau bizkaitarrek, Juan Iñiguez de Ibarguen eta Cachopin doktorearen semeak idatzi zutenean Ibarguen-Cachopin bezala ezagutzen den kronikan, hau da, Simancas-eko artxiboan kontserbatzen den Ystoria general española y sumaria de la casa de Vizcaya delakoan, hainbat testu faltsu sartzea.

Hauetako bi Andramendiko idazki apokrifoak bezala ezagunak, prosaz idatziak eta 564 eta 748. urtekoak omen zirenak, baina Koldo Mitxelenak eta Milagros Bidegainek garbi utzi zuten, ordea, testuen faltsutasuna 1954ean. Fortuna gutxiko testua izan zen hau. Baina bestea Leloren Kanta legez ezagutzen dena, Floranesen kopia batean Madrideko Liburutegi Nazionalean ikusi ahal izan duguna, lehen aldiz 1817an Humboldt-ek argitaratu zuen Berlinen. Eta honek fortuna hobeagoa (?) izan zuen Guilhem Humboldt (1767-1835) hizkuntzalariaren itzulpen eta interpretazio okerraren ondorioz.

Humboldt-ek Euskal Herrira bi bidaia burutu zituen 1799 eta 1801ean, animaturik Herderrek euskaldunei buruz esandakoekin, alegia, espero zuela laster Macphersonek gaelikoen historia, hizkuntza eta ohituren alde egindako lana bigarren Larramendi batek egitea euskaldunen alde, hauen jenio nazionala, alegia, kantak bilduz. Baina berehala konturatu omen zen kanta nazionalei zegokionean etsi egin beharko zuela, zeren itxuraz hain izan ziren sutsuak lehen euskal kristauak beren pagano garaiaren aztarrenak ezabatzen non ia ez zen deusere gelditu zutik. Hilabete eta asteegunen izenak, izen propio, dantza eta kantu batzuk soilik. Hauen artean bazen bat, akatsez josia, eta arrazoin zenbaitengatik bere zahartasuna dudan jar zitekeena. Hots, Leloren kantaz ari zitzaigun hitzegiten. Hau jakina den bezala honela hasten da:

Lelo il Lelo, Lelo il Lelo,
Leloa Zarak il leloa.
Erromako armak alegin eta
Bizkaiak daroa zantzoa.
Oktabiano munduko jauna
Leko bidi Bizkaikoa,
Itsasotati eta leorrez
Imini deusku moltsoa.

Zortzi lauko duen poema honek komentariogile ugari izan ditu eta hauen iritziak agertuko ditugu kronologikoki.

Pascual Gayangos y Arce (1809-1897) erudito, bibliofilo, eta arabe irakasle sevillanoak Erdi Aroko lan ugari bildu eta argitaratu zituen eta iruzkindu zituen eskuzkribuen artean Lelorena daukagu. Honela titulatu zuen gaztelaniaz egindako kopia: Erezia o poema historial de la guerra cantábrica con el emperador Augusto en bascuence. Eta Kronikari jarraiki honela itzultzen zituen lehen bertsoak: Lelo! Murio Lelo; Lelo! Murio Lelo, Zara mato a Lelo, echaron el grito los Romanos, pero Vizcaya lleva el clamor del triunfo. Octaviano, sentor del mundo, pero no de Vizcaya. Ast por mar como por tierra nos ha puesto el bloqueo, nos ha estrechado.

Lehen bertsoa Ibarguen-Cachopin agiriak dioenez, konpreniezina da baina antza denez sarrera hori honela esplika daiteke. Zara delako bat Totarekin, Leloren emaztearekin etzan zen, - 'mantuvo comercio adulterino' dio gaztelaniaz 
kronikak - , Lelo gerran zegoen bitartean, eta honen emaztea izorra gelditu zelarik bururatu zuten Lelo herrira itzultzean hiltzea. Hala egin zuten Zarak eta Totak, baina krimena agerian gelditu zelarik Zaharren Batzarrak lurraldetik akazatuak izan zitezen erabaki zuen, eta aurrerantzean kanta guztiek Leloren desgrazia aipa zezatela. Hemendik omen dator, noski Betiko leloa dioen esaldia.

Ixtorio honek dudarik gabe Agamenon, Argos eta Mizenasko errege legendarioarenarekin zerikusia badauka. Homerok kontatzen duenez Iliadan, Agamenon bere ema-esklabo Kasandrarekin itzuli zenean Troiako gerlatik Klitemnestrak eta honen amorantea zen Egistok hil egin baitzuten. Ixtorio honek literatura arrakasta haundia izan du, zeren Homeroz at besteak beste, Eskilok, Euripidesek eta Senekak ere erabili baitzuten beren tragedietan.

Interpretazio honen lehen kritika Michel-ek egin zuen, esaten digunean bere ustez, Lelo il lelo, etabar, esamolde huts bat besterik ez dela, flonflon edo tralala baten antzekoa, eta kasu honetan gaztelaniazko erromantze batetik datorrena hain zuzen, honen hasiera ezaguna hau delarik:

$$
\begin{aligned}
& \text { ¡Helo, helo por do viene } \\
& \text { el infante vengador, } \\
& \text { caballero a la jineta } \\
& \text { en un caballo corredor! }
\end{aligned}
$$

Ibarguen eta Cachopinen testuak hitz zahar, galdu eta ezezagun asko zituela, - zioen Michelek - , eta ezin zuela hauen esanahia eman erretserba handiz ez bazen.

Michelek 1857an hori bazioen, urte batzu geroxeago Bladé-k 1869an bere Les Basques d'apress les chants hérö̈ques, artikuluan argi uzten du apokrifo hau benetazko euskal testua izan balitz ez zukeela eramanen zituen, besteak beste, ondorengo latinismo hauek: arma, munduco, grandeza..., eta, beraz, asmakizun hutsa zela bere antzinatasuna, testu faltsu bat zela. Julien Vinson-en hitzetan, [il] fait une excellente critique des pastiches médiocres que des «farceurs» ont trop longtemps voulu imposer au monde savant. Alegia, testu faltsariek luzaro ahalegindu zirela jakintsuen munduari ziria sartzen erdipurdiko pastitxeak erdituz, baina hauen salaketa bikaina egin zuela Bladé historialari kritikoak.

José Antonio Azpiazu ez zen, antza denez, kritika hauetaz jabetu ere egin, ezen Barbieriren legadoan aurkitutako 1872 an burutu zuen Cantos Vascongados izeneko lanean, honakoa dio, la semejanza y estilo entre este canto y nuestros antiguos romances salta a la vista, cuya sencillez y candor revela idéntico origen en su composicion. Garbi dago zenbait idazlek poesia edota herri kantei buruzko komentarioak egiten dituenean ohiko lelokeriak besterik ez dakiela errepikatzen.

Vinson, hizkuntzalari eta bibliografo ongi jantzi eta zorrotzak, beraz, Pariseko Revue de linguistique-ren (1883) orrialdeetan garbi utzi zuen Leloren kanta, hala nola aurrerago aipatuko ditugun beste batzuk hain zirela modu zabarrean moldatuak, - fabrication grossiere-, non beraxek faltsu susmoak sorrarazten zituen. 
Asmakizun honekin batera etorri zen beste bat. Alegia, Lekobide delako pertsonaia erromatarren kontra altxatu zen euskal gudarien buruaren izena bezala asmatzen zuena. Hain izan zen gainera arrakastatsua pertsonaia horren asmakizuna, antza denez, ezen teatro munduan jarraikilerik ere izan baitzuen XX. mende hasieran. Besteak beste, Emiliano Arriagak 1913an plazaratu zuen Lekobide, tríptico legendario de cuadros líricos obra eta Emeterio Arresek Zara antzerkitxoa ere argitaratu zuen urte berean Tolosan Nere bidean, poema liburu barnean. Eduardo Mokoroak eresaldu eta zati batzuek Tolosako abeslari-taldeak urte bereko euskal-jaietan kantatu zituen, koroak azken-abestia agerlekuaren barnekaldetik honela hasten zuelarik:

$$
\begin{gathered}
\text { ¿Lelo, Lelo, il Lelo } \\
\text { Zara-k il Leloa; } \\
\text { Zara'kin Tota, biyak } \\
\text { Elkartze gaiztoa... }
\end{gathered}
$$

\section{(Abesti au amaitu baño lentxeago sortzen da oztadar edo uztargia.)}

Faltsutze hauen aurka altxatu zuen bere ahotsa Juan Karlos Gerra historiagileak, testu eta kantu zaharrez mintzatu zelarik (Los cantares antiguos del euskera, 1926), esanez hitzen aukera eta perpausen moldaketak argi adierazten zutela ez zela Karlos V.aren garaiko fabrikazio bat baizik. Dena den jarraikitzen zion Oktabiano / Lekobidi oposizioa mantentzeari, interpretazio oker honek irauten zuelarik 1978an oraindik Idoia Estornesen lanetan, mintzo zenean antzinako kantuez.

Koldo Mitxelenak, hizkuntzalari eta filologo zorrotz gisara azkenean jarri behar izan zituen gauzak bere lekuan, eta testuei beren jatorrizko esanahia eman «Contra Lekobide» (1986) izeneko artikulu gogoangarrian. Bertan frogatzen zuen argi eta garbi Lekobide ez zela izan erromantiko buru bero batzuen asmakizuna baizik, eta antroponimo bat izan ordez, lehen itzultzaileek ongi eman zuten bezala beren ordainetan aditz bat zela, lekot, lek(h)at, leko bidi, hau da, gaztelaniaz lugar no tuvo, excepto, exceptuese'. Hots, Oktabiano mundu guziko jauna, Bizkaikoa ezik, zicela bertsoak, eta eresia ez zela interpretatu behar Humboldt-ez geroztik bezala, hala nola, 'el supuesto triunfo de un supuesto Lekobide sobre Octavio Augusto', aipatzen zuen kanta zaharra gisa, baizik eta XVI. mendeko apokrifo baten moduan, non ez zen Lekobiderik inon argitzen.

XVIII. mendean Ingalaterran testu apokrifogileen mugimendu berezi bat hasiko da, baina ikusi dugun legez bazuen aintzindaririk, noski.

Thomas Gray (1716-1771) poetak The Barde deitu poema argitaratu zuen 1757an, geroago etorriko ziren poema osianikoekin antza eta berdintasun nabarmenak zituena. Honela hasten zen:

On a rock, whose hauggthy brow Frowns o'er old Conway's foaming flood, Robed in the sable garb of woe, With haggard eyes the Poet stood. 
Hots, Conway zaharrean uhin afarrez betetako harkaitz baten puntan, doluzko jantzi ilun batez estalia, begiak basa zegoen Poeta. Eta poema honen ondoren 1736an Ruthven-en jaio eta laborarien seme zen James Macpherson-ek, saio poetiko zenbaiten buruan The Poems of Ossian argitaratu zuen 1773an. Bai sorkuntza honek, bai Percy- $\mathbf{k}$ Edinburgon plazaratu Reliques of Ancient English Poetry (1765-1775) arrakasta haundia izan zuten Europa guztian.

Frantzian Le Journal Etranger errebistan jada 1780an hasi ziren zati zenbait itzultzen eta ezagutarazten. Itzultzaileen artean Turgot, Le Tourneur eta Diderot bera zeuden. Châteaubriand-ek 1793an Londresen Smith ediren zuen, Macpherson-en imitatzaileetarik bat, eta liluraturik estilo gotikoaz bidenabar Ossian-en aipamena egingo du Mémoire d'Outre-Tombe ospetsuan. Lamartine, Victor Hugo, eta Balzac gaztea ere Ossianen sukarrak harrapatu zituen, eta nobela gotiko gehienak ere erromantizismo britaniar hartaz kutsaturik gertatu ziren.

Italian Cesarotti abadearen inguruan biltzen ziren zaleak, Paduan hain zuzen, eta talde ossianiko bat sortu zuten, non partaideek poemetako pertsonaien izenez bataiatzen zituzten beren buruak. Cesarotti Aita Ossian zen, Barbieri Oscar, eta Venezian sortu emakumeen batzarre batean bazen Malvina izena ere hartu zuenik. Ossianismoak bigarren mailako poetengan batez ere eragina Italian bazuen, lehen mailako eragina izango du opera erromantikoan. Rossini-ren La Donna del Lago ez da Walter Scott-en Lady of the Lake itzulia baizik. Halaberetsu Bellini-ren I Puritani eta Donizettiren Lucia di Lammermoor Scotten jarraitzaile eta ondorioak dira. Verdi-ren Il Corsaro Byron-en obratik hartua da, noski, eta berdin Rossinik egiten duen Shakespeare-ren Otello-a azentu eta giro ossianikoz jantzia dago erabat.

Alemanian Johann Gottfried Herder (1744-1803) , Kant-en ikaslea izan zen sortu zuena 1770 urte inguruan herri poesiaz teoria oso bat. Pentsatzen zuen antzinako herri poesia gizatalde oso baten pentsamoldea zela, gizarte eta aro berezi bat agertzen zuena. Eta poeta modernoen oinarri behar zuela izan gainera. Hala, Ossian itzuli zuelarik bere teoriaren oinarrietariko bat gertatu zen. Honi jarraitu zioten, Klopstock, Goethe eta Schiller berak, eta ia musikari aleman handienek Ossian-en irudi musikala eman zuten: Schubert, Brahms, Mendelssohn, Dittersdorff... eta bestek.

Ez da harrigarri gertatzen bada Euskal Herrian bi kazetari saltsa-maltsari handi, Eugene-François Garay de Monglave eta Agosti Chaho nahastea mugimendu honetan eta bere hondar alea erromantizismoaren pizkunde berrian ezarri nahi izatea.

Garay de Monglave (1796-1873) Baionan jaioa, Parisera joan zen bere ikasketak egitera eta hemen poeta eta nobelista batekin ezkondu zen, JulieDelphine-Octavie De Casso-rekin. Bere biografia eta historia lanak pila dira eta denak aipatzea luzexko joko bailiguke hemen, hona batzu: Histoire de L'Espagne (1825), Histoire du Mexique (1825), Conspiration des Jésuites en France (1825) eta Histoire de Turquie (1826). Eta eleberrien artean aipa ditzakegu ere: Mon Parrain Nicolas (1823), eta Octavie, ou la Maitresse d'un prince (1825)... 
Pariseko Journal de L'Institut Historique delakoan 1835ean argitaratu zuen Altabizkarrako Kantua edo Chant d'Altabiscar edo akats eta guzti egileak idatzi zuen bezala Altabifar. Roland hilik gertatu zen Orreagako bataila famatuaz ari zen. Kanta aurkezten zuen artikuluan lehenik euskaldunez mintzo zen, hauen hizkuntzaz eta erabiltzen zituzten abestiez. Altabiçar delako kantaren kopia Garat kontearen etxean aurkitu omen zuen, eta honek La-Tour-d'Auvergne famatuari zor omen zion. Hau Iraultza Frantsesaren garaian Donostiako kapitulazioaz arduratu zen 1794ko abuztuaren 5ean, eta zioenez, hiriko kaputxinoen komentuan aurkitua zuen, eta bere ezaugarrien arabera XII edo XIII. mendeetakoa zitekeen, beraz, gertakizunaz lauzpabost mende geroagokoa.

Garbi dago Dominique Joseph Garat-ek ezin ziola ezezkorik eman 1833an hila baitzen Uztaritzen, eta Théophile Malo Corret de La Tour d'Auvergne, zelten kontuetaz arduratu zen militarrak ere ez, 1800ean zendua zenez. Donostian, aldiz, ez zen kaputxinoen komenturik garai hartan.

Dena den, hasieran idazle eta jakintsu zenbait engainuan erori ziren hala nola Mary Lafon, A. du Mêge eta Francisque Michel. Ziria ontzat jo zuten idazle guztien zerrenda eta zango-sartze galantak Vinsonek punduz-pundu salatzen ditu, eta frogatzen nola kanta Parisen konposatua izan zen 1834ean.

Baina Vinsonek salaketa egin aurretik, Michelek ancien popular poetry, antzinako herri poesiaren mostra bezala kontsideratu zuenean Gentelman's Magazine-n 1858an, Anton Abbadiak 1859an errebista berean erantzun zion argi eta garbi testu hura lehenik frantsesez moldatua izan zela hogei ta lau urte lehenago eta gero beste batek euskarara itzulia. Ez zuela euskarak, Europako hizkuntzarik zaharrenetarikoak horrelako asmakizun eta zaharreria faltsuen beharrik. Berehala Michel konturatu zen erruaz, idatzitakoa zuzendu zuen, eta aitortu zuen bai Altabiscarraco cantua bai eta Abarcaren cantua apokrifoak zirela, are forgeries.

Iritzi hau zabaldu zuten geroxeago xehetasun guztiak emanez Bladé historialariak 1866an bere Dissertation sur les Chants herroiques des basques, delakoan,Wentworth Webster ipuinbiltzaileak bere Basque Poetry txostentxoan 1879ean eta Vinson hizkuntzalariak 1884ean, bere Les Chants Historiques Nationaux izendatu artikuluetan.

Dena den apokrifo horrek bazuen ziria sartu ahal izateko zati bat benetazkoa, hau da, zenbakien zerrenda, zein benetan herriak kantatu egin izan duen.

Frantsesetik euskarara itzuli zuena Louis Duhalde izan zen. Hau ez zen inoiz haurtzaroan ikasitako euskaraz arduratu. Itzulpena aztertuz gero ikusten da, beraz, aski kaxkarra dela darabilen euskara, eta gainera ez neurri ez eta errimarik gabe dagoela itzulita. Badirudi Duvoisin eta honen lehengusu Duhaldek irri aski egin zutela asmakizunaz ikusiz zein engainaerrezak ziren hainbeste ospe eta fama zuten idazle jakintsuak.

Garay de Montglave ez zen konformatu ziria behin sartze ahaleginaz eta 1852an Villemain Heziketa Publikoko Ministroari bidalitako gutunean zioen, kantuaren itzulpena, si remarquable par son élegance et son exactitude, berea zela. Loreak bere buruari gezurrarekin batera. Alajaina! 
Ministroak agindu zion Euskal Herrira joan zedin eta bertako artxiboetan bila zitzala euskaldunen kanta zaharrak. Monglave-k burutu bidaia honen fruitua igorri zion. Hemeretzi chants nationaux, tartean hiru apokrifo: Lelo, Altabiçar (sic) eta Annibal-en kantuak. Halaber beste bi kanturen itzulpenak omen zirenak: Urthubiako alhaba eta Domingoren eresia. Hau 1853ko maiatzaren 9an gertatzen zen. Ministroak abuztuaren batean orijinalak eskatu zizkion, eta orduan bai benetazko itzulpena egin behar izan zuela, zein abuztuaren 12 an igorri zion.

Urthubiako alhaba, h-rik gabe Zavalaren 1998ko bertsioan eta Gainkoak (sic) deizula egun on... titulupean ematen diguna -, kanta tragiko bat da, eta zioenez apokrifogileak, Aphalh delako atso baten ahotik jasoa zuen. Historio xahar hura, Urthubiako alabak Frantziako errege bati birjinitatea ez eskaintzeagatik bere gurasoak urkabera bidaltzen zituela kontatzen zuena noizkoa ote, ordea?.

Zein ote zen errege gaizto hura, galdetzen zuen Monglavek. Charles VIIa 1442an Gaskoina aldetik ibili zena, edota Gaztelako Enrique IVarekin Urhubiako Gazteluan 1462an bildu zen Louis XI-a? Ez zuen erantzun zehatzik eman, ezin zezakeenez, beraxek, Macpherson-en Ossianen Kantuak irakurri ondoren, asmatuak baitziren.

Domingoren eresia, beste kanta apokrifoa esku berak egina dirudi, eta Vinsonen hitzetan elle trahit la même inexperience. Hots, berdin berdina da, lapurteraz idatzia eta hizkuntza akatsez josia. Honen iturburu historikoa hauxe da gure ustez, baina bada alderik historiatik ixtoriora irakurleak ikusiko duenez.

Maria Urthubikoa 1460. urtean Jean de Montreal-ekin ezkondu zen. Montrealgo jauna Louis XI-arekin gerlaz-gerla Alemania, Flandes eta Italia aldean ibili zen hogeita hamar urte luzez inolako albisterik eman gabe emazteari eta familiari. Maria, hila zela pentsaturik, 1469an Rodrigo Gamboa Alzatekoarekin berrezkondu zen, eta honen heriotzean, hots 1493an, agertu zen lehen senarra emaztea epaietara eramanez eta bere hondareak eskatuz Bordeleko Parlamentuan, baina Mariak burua makurtu baino lehen nahiago izan zuen gaztelua erre eta ihes egin, Beran hil zelarik 1505ean. Horra historia.

Begira orain honen bertsio apokrifoa nola gelditu zen Monglave eta bere itzultzailearen hitzetan. 1884az geroztik berrargitaratu ez denez, eta Zavalak ere jaso ez duenez hona testua: 


\section{DOMINGOREN ERESIA}

Nor da, nork jo egiten du horren goizik

Iholdiko azkeneko etxean?

Etxeko-jaunak, nausiak.

Españia guzia korritu ondoan,

Maitiaren sorprenitzerat heldu da.

Alba izarrak ez du oraino argitzen,

Izekia, txakur etxe guardariak

Ezagutu du aberiaren pausua,

Hirur hilabetez eskas zen

Eta Izekiak ez du sangatu.

Domingo, zerbitzari fidelak,

Ezagutu du, horrek ere, aberiaren pausua,

Eta jalgi da bortaren gainerat,

Gabazko aizeak argia ixten du,

Zoin itsa den, Domingo.

Etxeko jauna laguntzen du aberearen gainetik jausten,

Itz bat erran gabe,

Zeren Domingo badu zonbat errangia,

lzekiak Domingo baino alegerago,

Milikatzen du hazi duen eskua.

Etxeko-jauna hunadurak aurdikia da,

Lasterrago heltzeko bortxadu aberiaren pausua,

Etxeko-jauna gaixoa!

Mundu guziak maite eta altxatzen duena!

Zergatik hola presa?

Bainan jin nahi du laster besarkatzerat,

Maitena, bere bihotzeko adixkidea!

Geldi hor! Erraten du Domingok.

Denbora berean haiziak zabaltzen du borta,

Eta erakusten dio Maitena asasinatua.

- Ai ene Jainkoa! Ene Jainkoa! -Etxeko-jaun gaixoa!

- Hilzalea? - Ni! -Tristea! Ez, ez!

- Baina hura? - Bai. -Partalera? - Zure aneia.

- Gero? - Biak asasinatuak. - Nortaz? - Nitaz.

- Mila esker, Domingo! Ongi da!

Eta etxeko-jaunak, zutik bortaren gainean,

Xukatu zuen azkeneko nigar lodi bat,

Su eman zion etxeari;

Besarkatu zuen Domingo; ferekatu zuen Izekia.

Eta hirurak joan ziren aberearekin eta ez ziren gehiago agertu. 
Testua gaurko grafiara ekarri dugu, Vinson-en aurkezpen berari, - hau oso zorrotza izan arren-, zuzenketa zenbait eginez (do > dio, hilçaba $>$ hilzalea, haun > jaun, bessarhatu > besarkatu...).

Ixtorio honetan, - non bertsoek sei silaba izatetik hogeita bost edukitzeraino iristen diren, inolako errima ez erritmo zehatzik gabe -, beste kanta anitzetan bezala fidelitatea da gaia eta senarra gerratik itzultzean sortzen den tragedia. Adulterioaren aurrean bitxia dena da, ordea, hemen hiltzailea edo justizia egilea, ohorea garbitzen duena ez dela nagusia, morroia baizik.

Macpherson-en ikerleek diotenez honen baladetan emakume asko ageri dira sufritzen edota hiltzen, eta honek, beraz, egilearen nortasunaren sadomasokismoaren bortitza adierazi nahiko luke. Berdina ote Monglaveren kasuan? Garbi dagoena da, Macpherson maila apal batetik Britania Handiko gizatalde aberatsenekin harremanetan egotera eta enkarguak edukitzera iritsi zela, edo bederen hauen zirkuluetan murgildu zela. Halaber, Monglavek Frantziako Heziketari egindako zerbitzuen ordez Chants Nationaux Basques et Chants Nationnaux Béarnais-en deskubrimendua zela eta Gor-mutuen Inspektore izendatu zuela Gobernuak eta lehen mailako ospea aurkituko zuela eruditoen artean. Baina ez zion honek luzaro iraun.

Garay de Monglaveren joko apokrifogilea ez zen gelditu Altabiçar, Urthubiako alhaba eta Domingoren eresian, zeren Ministroari 1852an idatzi gutunean aurkezten zizkion ere berak 1821eko urriaren batean Hondarribiko kaputxinoen komentuan kopiatu omen zuen Annibalen kanta. Bi estrofa bidaltzen zizkion, eta hauek noski, Agosti Chahok 1845ean Ariel-en argitaratutakoak ziren. Lehena eta azkena. Bien artean sei ziren, baina hauen bertsioa frantsesez bakarrik eman zen Jean-Martin Hiribarrenek moldatu itzulpena eta Pierre Andiazabalen paperen artean neronek aurkitu eta plazaratu arte 1992an. Hau beraz, Chahoren fantasia besterik ez da, - alegia Annibalek berekin Italian barrena eraman euskal soldadu batek moldatu kantuarena -, zeini ezarri zizkion sarrera eta bukaerako zuberotar herri kanta baten bertso ederrak.

Jean-Martin Hiribarren (Azkain, 1810 - Baiona 1866) idazlea antza denez Chahoren adiskidea, liburu eta bertsoegile amorratua izan zen itzultzailea. Honek argitaratu zituen liburuen artean hor daude Montebideoco berriac (1853), Eskaldunac (1853), eta hil ostean Xipri Arbelbidek plazaratu 891an eskaldun gerla antzerki historikoa (1991), Rosa Miren Pagolak editatu Napoleon lehena biografia bertsotan (1994), eta neuk moldiztegiratu Irunteko bestak, 1845 poema (2001), besteak beste. Historia zuen gogoko, noski, eta garaiak hain maite zituen poema historikoak, tartean apokriforen bat edo beste idazten ahalegindu zen.

Hauetarik bat, Abarkaren Kanta izan zen. Michel-ek 1858an Gentlemen's Magazine-n plazaratu zuena aurkezpentxo batekin. Bertan Michel-ek zioen, Inchauspe abadeak igorri ziola esanez, antzinako poema behar zuela izan eta ez bizi zen poetaren baten irudimenak eta lumak sortua. Oraingoan ere berehala atera zen plazara Anton Abbadia, erantzunez 1859ko martxoan, Abarca's song delakoa bi urteko haurra besterik ez zela, eta egilea bizirik zegoela. Gainera berak antolatzen zituen Koplarien Guduak sarira 1858an aurkeztua izan zela, eta aipamena ere lortua.Dena dela XIX. mendeko euskal poesia anitz ingelesera itzuli ez denez hona lehen estrofa Michel-ek eman bezala: 


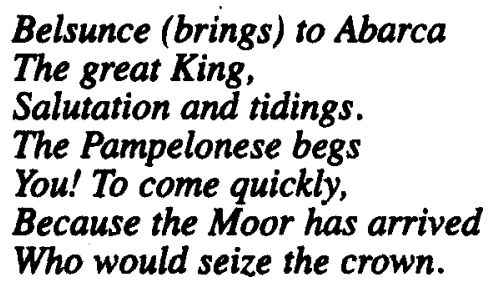

Moroen eta orientalismoaren moda hedaturik baitzen bai arkitekturan, bai bidaietan, bai eta literaturan, euskal literatura ere ez zen mugimendu orokorretik urrundu, ez eta kutsatu gabe gelditu.

Iparraldeko apokrifoen jokaera hori ez zen Bidasoaz haraindian soilik eman, hegoaldean, bi ixtoriozalek, bat Joan Benantzio Arakistain debarrak (Deba, 1828Tolosa, 1906) eta bestea Klaudio Otaegi zegamarrak (Zegama,1836-Hondarribi, 1890 ) bereak asmatu baitzituzten beste zenbait kasutan bezala tradizioan oinarrituz.

Lehenak Tradiciones vasco-cántabras (1866) ipuin bilduman Beltran Aloskoaren eresia eman zuen. Egileak Guerrari kontatu zionez, atso zahar baten ahotik jasoa zuen kanta eta hitzez-hitz transkribitua. 1865ean bildua emakumeak laurogeita zortzi urte zituenean. Ene uste apalez, Alos-torria, bai, Alos-torria! bertsolerroaz eginiko laukoaz at beste dena, Guerraren esanak esan, apokrifoa dela, bai moldez bai ixtorioaren hizkeraz modernoa sentitzen baitut, ez dutenak ezer ikustekorik urrundik baizik, adibidez, Garibayk bildutako Milia Lasturkoaren bertsoekin.

Halere izan zuen mende bat geroago ere jarraikilerik Arakistainek, 1952an plazaratu baitzuen Nemesio Etxaniz (Azkoitia, 1899-Donostia, 1982) kantu egile, eleberrigile eta antzerkigileak Irulearen negarra, iru egintza ta atzezburua dituan zorigaitz-antzerkia ixtorio hartan oinarritua. Bere jaiotze mendeurrenean plazaratu zuen berriro Debako antzez-taldeak.

Bigarrenak Beotibarko kantua ondu zuen.Otaegik zioenez, haurtzaroan bere sorterrian ikasi omen zituen Beotibarko bertsoak, eta gero apaiz batek erakutsi omen eskuzkribu zahar-zahar eta ilun batean. Aitortu beharra dago gipuzkoarren eta naparren arteko koplen eskuzkribu hau ez dela sekula agertu. Halere, Gerrak uste du benetazkoa dela, baina beste sei bertso erantsi zizkion Arakistainek $E l$ Basojaun de Etumeta (1882) eleberrian ezetz, argi nabarmentzen dutela esku moderno eta arrotza. Nire uste apalez, Otaegik sortu zituen lehen zazpiak ere honek asmatuak dira. Dudarik gabe arrakasta haundia izan zuten XX. mendeko 60. hamarkadan Lurdes Iriondok maiz kantatzen baitzituen.

Arakistainek zuzenbide ikasketak egin ondoren kazetaritza lanetan ihardun zuen urte luzez Monglave eta Chahok bezala. Egiari ez zioten hiru kazetariek errespetu gehiegirik, antza denez, eta literaturarako jaidura nabarmena zuten.

Bestalde, Otaegi Hondarribiko maisua izan zen eta euskaraz poema historiko mordoa moldatu zuen, Hiribarrenen antzera.

Ikuspegi zabal batekin begiratuz apokrifoen mugimendua ondorioztatu behar dugu, ezen Nanni dominikoa ren kasuan bezala, honek ez bazituen kontraegin eta hedatu zati apokrifoak, benetakoen ikerketa ere ez zela eginen behar bezalako zorroztasunaz. Ziri sartze huts diruditen kamelo hauek sortu izan 
ziren modua salatzeko ere, azeri samarra behar zela izan eta faltsariekin harremanak eta tratua eduki izana.

Halaberetsu, eragile gisara, bada, izan zuten beren garrantzia, eta bai Karl Otfried Muller-ek bai Jesús Antonio Cid-ek sinpatiaz, esku-zabaltasunez eta begirunez aztertzen dituzte, zeren eta herri balada horiek faltsuak eta apokrifoak izan arren, Europako herrialde anitzetan balio izan zuten Estatu gabeko hainbat eta hainbat hizkuntza eta kultura berpizteko eta duintze bidean ezartzeko.

\section{BIBLIOGRAFIA}

ARRIOlabengoA, J., (1996), «Erdi Aroko kanta ezezagunak. Ibarguen-Cachopin kronikan (150-1620)», ASJU (Anuario del Seminario de Filología Julio de Urquijo), Donostia, 71-98.

AstaRLOA, P.P., (1803), Apología de la lengua bascongada 6 ensayo crttico filosófico de su perfección y antiguiedad sobre todas las que se conocen. G. Ortega, Madrid.

CiD, J. A., (1994), «Tradición apócrifa y tradición crítica en la balada tradicional vasca. I. Las falsificaciones de cantos populares en Europa, ensayo de tipología», ASJU, Donostia, 505-523.

GARAY DE MONGLAVE, E., Chants nationaux basques et chants nationaux bearnais. MS Bibliotheque Nationale de Paris, naf, $n^{\circ} 3340,3342$.

Grafton, A., (2001), Falsarios y crticos. Creatividad e impostura en la tradicion occidental. Crítica, Barcelona.

IBARGUEN- CACHOPIN, Ystoria general española y sumaria de la casa de Vizcaya. MS del Archivo de Simancas. Cuaderno 61.

Michel, F., (1857), Le Pays Basque, sa population, sa langue, ses moeurs, sa littérature et sa musique. F. Didot, Paris.

MrTXELENA K. \& Bidegain, M., (1954), «Las escrituras apocrifas de Andramendi», ASJU, I, 5-25.

MITXELENA, K, (1986), «Contra Lekobide», ASJU, XX-1, 291-313.

OSSIAN-MACPHERSON, (1990), Fragments de poésie ancienne. Col. Romantique n.. 23. Ed. José Conti, Paris.

PERCY, Th., (1776-1775), Reliques of Ancient English Poetry. Edimburgo.

Poljakov, L., (1994), Le mythe aryen. Essai sur les sources du racisme et des nationalismes. Calman-Levy, Pocket, Paris.

PozA, A., (1587), De la antigua lengua, poblaciones y comarcas de las Espafias en que de paso se tocan algunas cosas de Cantabria. M. Mares, Bilbao.

URKIzU, P., (1992), Agosti Chaho, Azti-begia eta beste izkribuzenbait. Elkar, Donostia.

ZavalA, A., (1998), Euskal erromantzeak. Romancero vasco. Sendoa, Diartzun.

Vinson, J., (1884), Notice Bibliographique sur le folklore basque. Maisonneuve frères. Paris.

WeBSTER, W., (1879), «Basque Poetry», Basque Legends. London, 235-276. 